\title{
Application of Dialectical Behavior Therapy in patients with opioid dependence- a pilot study
}

Komal Sancheti, Ph.D. scholar, Department of Clinical Psychology, Shree Guru Gobind Singh Tricentenary University, Gurugram, Haryana-122505, komalsancheti1995@gmail.com

Dr. Nandha Kumara Pujam S, : Associate Professor \& HOD Clinical Psychology, Department of Clinical Psychology, Shree Guru Gobind Singh Tricentenary University, Gurugram, Haryana-122505, Rehabilitation Council of India (RCI) No: A22180, Indian Association of Clinical Psychologists, PLM 478/10/14

\begin{abstract}
Background: Opioid dependency is a serious public health concern. India is one of the largest legal producers of opium and has an established pattern of use of opioid group of drugs. Opioid substitution therapy (OST) has displayed better outcomes compared with other existing treatment strategies. Dialectical Behavior Therapy (DBT) is a fast growing treatment modality used more and more to help individuals overcome addiction and maintain recovery. DBT incorporates concepts and modalities designed to promote abstinence and to reduce the length and adverse impact of relapses. DBT serves to improve patient motivation to change, enhance patient capabilities, generalize new behaviors, and restructure the individual's environment.

Aim: Present study was aimed to explore the effect of Dialectical Behavior Therapy (DBT) on level of severity of opioid dependence, distress tolerance, emotion regulation and interpersonal competence skills in patients with opioid dependence.

Methods: This study consisted of 40 patients diagnosed with opioid dependence syndrome .The selected patients completed their individual baseline assessment. Afterward the patients were randomly assigned to the Experimental and control groups equally. The patients in experimental group attended 13 twice a week 90 minutes' individual DBT sessions focusing on Distress tolerance, Emotion regulation and inter-personal competence along with their TAU. The patients in control group were only on their TAU. Base line assessment scores were obtained using Severity of dependence scale (SDS), Brief-Cope Questionnaire, Emotional Regulation Questionnaire (ERQ) and Interpersonal Competence Questionaaire-15 (ICQ-15). Analysis was done using SPSS v 25.0 software and Wilcoxon Singed Rank Test was applied. A p value of $<0.05$ was considered to be statistically significant.

Results: The experimental group (DBT+TAU) has proved effective in reducing levels of severity of opioid dependence, enhanced distress tolerance in domains (Self-distraction ,Active Coping ,Emotional support, Acceptance, Positive Reframing and Religion), better emotional regulation( cognitive reappraisal , decreased emotion suppression) and Effective interpersonal competence (Initiation, Negative Assertion and Conflict Management) than the control group (TAU).

Conclusion: Skills taught in DBT do seem to support the needed foundation of substance Dependence treatment; motivation for change, motivation to continue in treatment, and staying mindful of high-risk situations.
\end{abstract}

Keywords: Clinical Psychiatry, DBT, Emotional regulation, inter-personal competence, Opioid dependence.

Received: 07.12.2020 Accepted: 22.01.2021 Published: 02.02.2021




\section{INTRODUCTION}

Substance dependence is a serious public health problem. It not only causes impairment and suffering on the part of the affected individual, but also creates a significant burden for the family and society. It is well known that opioids are one of the world's most problematic illegal substances. According to one of the theory of addictive behavior, known as the "self-medication hypothesis" (SMH) individuals use drugs and alcohol to modulate their emotional states ${ }^{[1]}$.There were an estimated 33 million opioid users globally in 2014, much less than 184 million cannabis users ${ }^{[2]}$. However, among the illegal substances, opioid dependence is the highest contributor to the number of disability-adjusted-life-years lost (9.2 million) and to drug-related deaths (43.5 deaths/million people aged 15-64 years) ${ }^{[3]}$.The national survey of India (2004) published estimates the frequency of current opioid use to be $0.7 \%$ in general population. This parallels to 2 million current opioid users and 1 million of them are opioid-dependent ${ }^{[4,5]}$. Another concern is route of administration of opioids which is injecting. There are about 12 million injecting drug users (IDUs) globally, who face some of the most severe harms including blood-borne infections, HIV, hepatitis C and deaths due to overdose ${ }^{[5]}$. There are various strategies that have been applied to manage opioid dependence, not all of them are equally effective and viable. Detoxification alone or antagonist maintenance therapy with naltrexone results in high relapses also less acceptable to patients ${ }^{[6]}$. Agonist maintenance treatment with opioids (commonly referred to as opioid substitution therapy [OST] in India, has displayed better outcomes compared with other existing treatment strategies but is not focused on holistic well-being of the patient. OST helps the patient to be part and continue the treatment by just reducing intake frequency of opioids and other substances. ${ }^{[7]}$

Marsha Linehan in 1980 developed the Dialectical Behavior Therapy (DBT) ${ }^{[8]}$ which focuses on both cognitive and behavioral aspects of the psychological treatments. A successful DBT intervention help the patient learn to predict, communicate, pursue, and maintain goals that are independent of their history of outof-control behavior, substance abuse and poor coping with life's day to day problems. DBT focuses on larger therapeutic goal than decline in problem behaviors, symptom management or reassurance of the client. The core principle of DBT is to create "a life worth living" and promote two opposed goals for patients which are: change and acceptance" [9]. It is an evidence-based psychological treatment that was developed to reduce suicide attempts and self - harm behaviors ${ }^{[8]}$. DBT was further improvised to treat Borderline Personality Disorder (BPD) ${ }^{[10]}$ and several controlled trials validated its effectiveness ${ }^{[11]}$ also, DBT likewise proved to be effective in reducing substance-related behaviors among patients with BPD ${ }^{[12]}$. DBT-ST has been implemented as a stand-alone intervention for several clinical conditions ${ }^{[13]}$ including Alcohol Use Disorder (AUD) ${ }^{[14]}$. Studies conducted on AUD, showed that the rate of lapses and drop-out were low during a 3- month DBT-ST program. When the intervention was fully carried out in outpatient setting there were large improvements in difficulties with emotion regulation (DER) ${ }^{[14]}$. This proved to be evidence in support of DBT as treatment of individuals with a key diagnosis of substance use disorders (SUDs). The viewpoint that substance abusers have difficulties regulating their emotions, and that negative emotional states precipitate substance use, is supported by a large body of empirical evidence ${ }^{[42]}$ DBT as defined within the broader context of the field of psychology, is a skilled and inclusive treatment process whereby the thoughts, feelings, and behavior of a person are modified with the intention of facilitating increased functioning and life adjustment. Emotional regulation is more important than any other factors in relapse prevention. ${ }^{[16,17]}$

Most researches on the effectiveness of treatments for Substance dependence disorders focuses on indexes quantity of substance intake as primary outcomes. However, this approach is questionable as when we consider comprehensive treatment and over all wellbeing of the patient several other indexes related to multiple domains of addiction pathology (e.g. substance withdrawal, craving, subjective substance effects) and psychological functioning (e.g., stress, coping, self-efficacy, inter-personal effectivity etc.) are considered, which extends beyond the quantity and frequency of substance intake ${ }^{[18]}$ Implementation of DBT intervention for SUDs should be considered as a part of treatment as it focus on all the core psychological elements which leads dependence with respect to other relevant clinical aspects in addition to abstinence maintenance. 
Hence, this pilot study was conducted with an aim to explore the effect of Dialectical Behavior Therapy (DBT) in reducing the severity of dependence, enhancing distress tolerance, emotion regulation and interpersonal relationship skills in patients with opioid dependence.

\section{Hypothesis}

$>$ There will be no significant effect of DBT on level of severity of opioid dependence, Distress tolerance, emotion regulation and interpersonal competence skills among the patients with opioid dependence.

\section{MATERIAL AND METHODS}

This was a randomized controlled study. The study was primarily conducted in a psychiatric ward (SGTU) from August 2019 to May 2020. Present study was approved by Institutional Ethical committee of Shree Guru Gobind Singh Tricentenary University (SGTU/FBSC/ECA/2020/08). This study was consistent with the code Of conduct for research in psychology and was in line with the ethical principles of the American Psychological Association, 2017.

A preliminary clinical interview by a senior psychiatrist was conducted to confirm the diagnosis of opioid dependence syndrome as per ICD-10 (DCR) ${ }^{[19]}$ and to evaluate the presence of other psychiatric disorders to support the reliability of assessment procedures before the admission of patients to the treatment. The patients were selected based on the inclusion and exclusion criteria .

\section{INCLUSION AND EXCLUSION CRITERIA FOR EXPERIMENTAL GROUP:}

\section{Inclusion criteria:}

- Patients diagnosed as having opioid dependence syndrome according to ICD-10 (DCR) criteria

- Patients of aged 18 to 50 years

- Male patients

- Able to speak, read, and write Hindi language

- Able to provide formal informed consent

- Patients with length of dependency till 5 years.

- Both IPD and OPD patients were considered to be part of sample

- Patients in pharmacotherapy(treatment as usual)

\section{Exclusion criteria:}

- Patients with co-morbid substance dependence (except nicotine) with or without psychotic symptoms.

- Patients with other co-morbid psychiatric diagnosis than anxiety and depression.

- Patient having organic illnesses (based on hospital data base).

- Patients should not be part of any other psychotherapeutic process.

\section{INCLUSION AND EXCLUSION CRITERIA FOR CONTROL GROUP:}

The inclusion and exclusion criteria for control group is same as experimental group but THE PATIENTS IN CONTROL GROUP DID NOT RECEIVE DBT.

In this study, to get the empirical evidence of the variables under consideration a sample of 40 patients were included. Afterwards, they were randomly assigned to the experimental and control groups using simple random sampling with 20 patients in either group. Patients were informed in detail about the objectives and implications of the study and how the results of the study will be used in the future. All patients provided informed consent prior to participation in the study and confidentiality was maintained throughout. Patients were allowed to withdraw at any given point of time during the course of study.

The socio-demographic and clinical details were collected using prepared semi structured data sheet. 
Before starting the therapeutic intervention a baseline assessment including measurement of severity of opioid dependence, emotional regulation, distress tolerance and interpersonal competence skills was conducted on the 40 patients individually.

Thereafter, therapeutic package of DBT skill training was applied among the patients of the experimental group in 13 twice a week - 90 minutes' individual sessions for duration of 8 to 10 week with their Treatment as usual (TAU). The patients in control group were only on their TAU. At least two random weekly urine toxicology screening tests were used to validate the abstinence maintenance during the treatment. After the successful completion of 13 DBT sessions for experimental group, both the group were assessed on same measure for post treatment scores.

\section{TAU: (Treatment as usual)}

- Consist of oral opioid substitution therapy (OST) which consists of following medicines list, given in combination and after diagnosing general health conditions of patients -

1. Tramadol (25 mg oral dose every morning initially; increase by $25-50 \mathrm{mg} /$ day every 3 days up to 50 $100 \mathrm{mg}$ orally every $4-6 \mathrm{hr}$ as needed; not to exceed $400 \mathrm{mg} /$ day)

2. Tapentadol (50-250 mg orally every $12 \mathrm{hr}$; not to exceed $500 \mathrm{mg} /$ day)

3. Buprenorphin (8 mg sublingually (SL) on day 1, then $16 \mathrm{mg}$ SL on day 2; continued over 3-4 days)

4. Benzodiazepine (5 to $25 \mathrm{mg}$ three times a day-four times a day, Maximum $40 \mathrm{mg} /$ day)

5. Clonidine (oral dose is $0.3-1.3 \mathrm{mg}$ day up to $10-14$ days, The maximum oral dose is $2.4 \mathrm{mg}$ daily)

- Intravenous drip (IV), it consists of DNS (dextrose and sodium chloride) for electrolyte correction and prevents dehydration caused due to absence of opioids.

- Two random weekly urine toxicology screening.

\section{Other Variables taken under consideration}

\section{Coping skills}

Richard Lazarus and Susan Folk man (1983) scientifically defined coping "as the sum of cognitive and behavioral efforts, which are constantly changing, that aim to handle particular demands, whether internal or external, that are viewed as taxing or demanding. [20] The Brief COPE ${ }^{[21]}$, self-report inventory was used to measure coping skills.

\section{Emotional Regulation}

"Emotion regulation" is a term generally used to describe a person's ability to effectively manage and respond to an emotional experience. There is an extensive literature linking poor emotional regulation to substance use and related problems in human studies, as has been reviewed previously ${ }^{[2]}$. It is also well known that heavy substance use can trigger impulsive behavior ${ }^{[23]}$. Emotion Regulation Questionnaire (ERQ), ${ }^{[24]}$ was used in this study to measure emotional regulation in the patients.

\section{Interpersonal Relationships}

Interpersonal relationships occur when two or more people interact with each other. This will often occur face to face. It is also possible to have such a relationship online without ever meeting the person in real life. These interactions may be brief or longer lasting. The different types of interpersonal relationship may include family, professional relationships, friends etc. The Brief ICQ $-15^{[25]}$ was used to measure the quality of interpersonal relationships of the patients.

\section{DBT Therapeutic Package}

The therapy consists each session of 90 minutes duration. The sessions were conducted twice in a week. Each patient in experimental group received 13 individual sessions in total. The whole package, activities and procedures were kept identical and homogenous for all the 20 patients. The skills were chosen from skill 
repertories of DBT skill training manual ${ }^{[26]}$ which were more relevant in the context of dependent variables. During the training for each skill the therapist used charts, diagrams and role-plays to demonstrate how the particular skill can be chosen and effectively implemented to handle the dysfunctional emotions, situations and events in both inter and intra personal perspectives. Best efforts were retained to keep each patient involved and attain best of their capabilities.

The initial phase of the therapy included rapport building and psycho-educating the patient about illness and explaining the treatment process and the assessment. The middle phase focused on improving distress tolerance skills, identifying emotions, letting go off emotional vulnerability and developing skills for effective interpersonal relationships. Termination phase included the summarization about the previous sessions, reviewing the progress and feedback from the patient. (Table: 1)

Table 1. Detailed intervention plan (DBT skill training manual [26])

\begin{tabular}{|c|c|c|}
\hline SESSIONS & GOALS & ACTIVITIES \\
\hline $\begin{array}{l}\text { Pre-intervention sessions } \\
\text { (2) }\end{array}$ & $\begin{array}{l}\text { The intent was to select the } \\
\text { appropriate patients for the } \\
\text { pilot study and establish } \\
\text { rapport. }\end{array}$ & $\begin{array}{l}\text { - } \text { Case history taking } \\
\text { - Rapport formation }\end{array}$ \\
\hline & $\begin{array}{l}\text { The purpose was to educate } \\
\text { about opioid dependence } \\
\text { disorder and role of } \\
\text { impulsivity, coping and } \\
\text { interpersonal skill in this } \\
\text { disorder and to provide } \\
\text { information for current } \\
\text { intervention with rationale. }\end{array}$ & $\begin{array}{ll}\text { - } & \text { Rapport formation } \\
\text { - } & \text { Psycho-education } \\
\text { - } & \text { Pre therapy assessment }\end{array}$ \\
\hline $\begin{array}{l}\text { Skill training for Distress Tolerance } \\
\text { (Sessions-3) }\end{array}$ & $\begin{array}{l}\text { The intent was to develop the } \\
\text { skill of effective distraction to } \\
\text { improve distress tolerance } \\
\text { and improve the skills to } \\
\text { improve the present moment } \\
\text { to enhance distress tolerance. }\end{array}$ & $\begin{array}{l}\text { - Distracting: Wise mind accepts. } \\
\text { - Improve the Moment }\end{array}$ \\
\hline $\begin{array}{l}\text { Skill Training for Emotion Regulation } \\
\text { (Sessions - 3) }\end{array}$ & $\begin{array}{l}\text { The intent was to develop } \\
\text { skills to identify and be } \\
\text { mindful about emotions } \\
\text { experienced. Also train to } \\
\text { modify the dysfunctional } \\
\text { emotion and let go of } \\
\text { emotional vulnerability. }\end{array}$ & $\begin{array}{l}\text { - Teaching emotional regulation } \\
\text { through - } \\
\text { - Ways to observe and describe } \\
\text { emotions } \\
\text { - Letting go of emotional } \\
\text { vulnerability }\end{array}$ \\
\hline $\begin{array}{l}\text { Skill training for Interpersonal } \\
\text { Effectiveness } \\
\text { (Session-3) }\end{array}$ & $\begin{array}{l}\text { The intent was to develop } \\
\text { skills for objective } \\
\text { effectiveness and to maintain } \\
\text { effective relationships by } \\
\text { improving self-respect of the } \\
\text { client simultaneously. }\end{array}$ & $\begin{array}{ll}\text { - } & \text { Interpersonal Effectiveness- } \\
\text { - } & \text { DEAR MAN } \\
\text { - } & \text { FAST }\end{array}$ \\
\hline Termination (2) & & - $\quad$ Termination of the therapy \\
\hline
\end{tabular}




\section{TOOLS}

$>$ Socio-demographic data sheet:

A semi structured form was prepared to collect the personal details of the patient like name, age, gender, education, occupation, etc. The clinical data sheet was used to collect the information about the illness of the patient, course, progress, mode, duration of the illness, etc.

$>$ Severity of Dependence Scale (SDS) ${ }^{[27]}$ :

The Severity of Dependence Scale contains total of 5-item in the questionnaire that provides a score indicating the severity of dependence on opioids. Each of the five items is scored on a 4-point scale (0-3). The total score was obtained by adding the scores for all the 5 items. A score $\geq 7$ indicates high level of dependence. The SDS score is related to behavioral patterns of drug taking that are - indicators of dependence, quantity of dose, frequency of use, duration of use, daily use and degree of contact with other drug users.

$>$ Brief COPE Questionnaire:

The Brief COPE ${ }^{[20]}$ is a self-report questionnaire used to assess a number of different coping behaviors and thoughts a person may have in response to a specific situation. It is made up of 14 subscales: selfdistraction, active coping, denial, and substance use, use of emotional support, use of instrumental support, behavioral disengagement, venting, positive reframing, planning, humor, acceptance, religion, and selfblame. It is a 28 -item self-report inventory using a 4-point frequency.

$>$ Emotional regulation questionnaire :

A 10-item scale ${ }^{[24]}$ designed to measure respondents' tendency to regulate their emotions in two ways:

(1) Cognitive Reappraisal and (2) Expressive Suppression. Respondents answer each item on a 7-point Liker-type scale ranging from 1 (strongly disagree) to 7 (strongly agree).

$>$ Brief Interpersonal Competence Questionnaire (ICQ-15):

The Brief ICQ - $15^{[25]}$ is a short version of ICQ which contains set of 15 questions. It assesses five separate domains of social competence: (a) initiation of relationships, (b) negative assertion, (c) disclosure of personal information, (d) emotional support and (e) conflict management. The items are rated on a 5-point Liker-type scale ranging from 1 to 5 .

\section{Statistical Analysis}

Statistical analysis was done using SPSS v 25.0. Non-parametric test were used (Wilcoxon Singed Rank Test \& Mann-Whitney $U$ test) to evaluate the changes in dependent variables from the beginning to the end of the treatment.

\section{RESULTS}

The mean age of the patients was $32.55 \pm 7.74$ years for experimental group and $35.6 \pm 7.24$ years for control group. The average education of the patients was Graduate for experimental group (with mean of $15.05 \pm$ 2.01 years) as well as for control group (with mean of $15.05 \pm 1.57$ years). The patients under experimental group have 2.3 years of average duration of opioid dependence and 2.4 years for control group (Table: 2 )

Table 2. Descriptive statistics for socio demographic variables

\begin{tabular}{|l|l|l|}
\hline Variables & Experimental Group Mean \pm SD & Control Group Mean \pm SD \\
\hline Age (Years) & $32.55 \pm 7.74$ & $35.6 \pm 7.24$ \\
\hline Education (Years) & $15.05 \pm 2.01$ & $15.05 \pm 1.57$ \\
\hline Duration of dependence (years) & $2.3 \pm 0.94$ & $2.4 \pm 0.93$ \\
\hline
\end{tabular}

6 |KOMAL SANCHETI DR. NANDHA KUMARA PUJAM S.
Application of Dialectical Behavior Therapy in patients with opioid dependence -a pilot study 


\section{Within Group Analysis - Experimental Group}

After the treatment, post test scores have shown significant decrease in severity of dependence with mean of $10.75 \pm 1.21$ from pretest scores with mean of $12.45 \pm 1.23$. The difference was found significant $(\mathrm{p}<.001)$. [Table: 3]

Table 3. Comparison of pre-post treatment test scores of Severity of Dependence for experimental group ( $N=20)$.

\begin{tabular}{|l|l|l|l|l|l|}
\hline Variables & $\begin{array}{l}\text { Pre } \\
\text { Mean } \pm \text { SD }\end{array}$ & $\begin{array}{l}\text { Post } \\
\text { Mean } \pm \text { SD }\end{array}$ & Z & Df & P value $^{\#}$ \\
\hline $\begin{array}{l}\text { Severity of } \\
\text { Dependence }\end{array}$ & $12.45 \pm 1.23$ & $10.75 \pm 1.21$ & -3.993 & 19 & $0.001^{*}$ \\
\hline
\end{tabular}

\# Wilcoxon Singed Rank Test, *Statistical Significant at 0.05

Table 4. Descriptive statistics and comparison of pre-post treatment test scores of Brief COPE Questionnaire for experimental group $(N=20)$.

\begin{tabular}{|l|l|l|l|l|l|}
\hline Variables & $\begin{array}{l}\text { Pre-treatment } \\
\text { Mean } \pm \text { SD }\end{array}$ & $\begin{array}{l}\text { Post-treatment } \\
\text { Mean } \pm \text { SD }\end{array}$ & Z value & Df & P value $^{\#}$ \\
\hline Self-distraction & $3.45 \pm 0.94$ & $5.8 \pm 1.01$ & -4.093 & 19 & $0.001^{*}$ \\
\hline Active Coping & $4.45 \pm 0.94$ & $6.45 \pm 1.05$ & -4.029 & 19 & $0.001^{*}$ \\
\hline Denial & $4.35 \pm 1.23$ & $2.85 \pm 1.04$ & -3.919 & 19 & $0.001^{*}$ \\
\hline Substance use & $6.65 \pm 1.09$ & $2.45 \pm 0.51$ & -3.975 & 19 & $0.001^{*}$ \\
\hline Emotional support & $5.5 \pm 1.00$ & $6.55 \pm 1.05$ & -3.384 & 19 & $0.001^{*}$ \\
\hline $\begin{array}{l}\text { Instrumental } \\
\text { support }\end{array}$ & $6.55 \pm 1.1$ & $6.7 \pm 1.17$ & -.656 & 19 & 0.51 \\
\hline $\begin{array}{l}\text { Behavior } \\
\text { disengagement }\end{array}$ & $7.25 \pm 0.79$ & $5.45 \pm 0.6$ & -3.982 & 19 & $0.001^{*}$ \\
\hline Venting & $5 \pm 1.08$ & $6.9 \pm 1.17$ & -3.985 & 19 & $0.001^{*}$ \\
\hline Positive reframing & $2.7 \pm 0.86$ & $4.4 \pm 1.10$ & -3.743 & 19 & $0.001^{*}$ \\
\hline Planning & $5.5 \pm 1.36$ & $6.95 \pm 1.05$ & -3.573 & 19 & $0.001^{*}$ \\
\hline Humor & $3.55 \pm 0.89$ & $3.45 \pm 0.6$ & -.707 & 19 & 0.48 \\
\hline Acceptance & $3.7 \pm 1.38$ & $5.95 \pm 1.00$ & -3.992 & 19 & $0.00^{*}$ \\
\hline Religion & $3.75 \pm 1.48$ & $4.55 \pm 1.54$ & -3.176 & 19 & $0.001^{*}$ \\
\hline Self-blame & $7.2 \pm 1.06$ & $6.1 \pm 1.07$ & -3.824 & 19 & $0.001^{*}$ \\
\hline
\end{tabular}

\# Wilcoxon Singed Rank Test, *Statistical Significant at 0.05

Among all sub-scales of Brief COPE Questionnaire, significant increases were detected for Self-Distraction $(\mathrm{p}<.001)$, Active Coping $(\mathrm{p}<.001)$, Emotional Support $(\mathrm{p}<.001)$, Venting $(\mathrm{p}<.001)$, Positive Reframing $(\mathrm{p}<.001)$, Planning $(\mathrm{p}<.001)$, Acceptance $(\mathrm{p}<.001)$ and Religion $(\mathrm{p}<.001)$ in comparison with its pre-test scores. Conversely, post test score of Denial $(\mathrm{p}<.001)$, Substance Use $(\mathrm{p}<.001)$, Behavior Disengagement $(\mathrm{p}<.001)$ and Self-blame $(\mathrm{p}<.001)$ shown significant decrease as compared to its pretest scores. However, no significant changes observed in pre-test and post-test scores of Instrumental support and Humor subscales. 
Table 5. Descriptive statistics and comparison of pre-post treatment test scores of Emotional Regulation for experimental group $(N=20)$.

\begin{tabular}{|l|l|l|l|l|l|}
\hline Variables & $\begin{array}{l}\text { Pre-treatment } \\
\text { Mean } \pm \text { SD }\end{array}$ & $\begin{array}{l}\text { Post-treatment } \\
\text { Mean } \pm \text { SD }\end{array}$ & Z value & Df & p value \\
\hline $\begin{array}{l}\text { Cognitive } \\
\text { reappraisal }\end{array}$ & $25.8 \pm 4.12$ & $27.25 \pm 4.01$ & -3.737 & 19 & $0.001^{*}$ \\
\hline $\begin{array}{l}\text { Expressive } \\
\text { suppression }\end{array}$ & $23.55 \pm 3.55$ & $21.65 \pm 4.34$ & -2.483 & 19 & $0.01^{*}$ \\
\hline
\end{tabular}

\# Wilcoxon Singed Rank Test, *Statistical Significant at 0.05

Post test scores of cognitive reappraisals shown significant increase than the pre-test scores $(\mathrm{p}<.001)$. Conversely, post test scores of expressive suppressions with mean of 21.65 shown significant decrease than the pretest scores with mean of $23.55(\mathrm{p}<.01)$.

Table 6. Descriptive statistics and comparison of pre-post treatment test scores of Interpersonal Competence Questionnaire for experimental group $(N=20)$

\begin{tabular}{|l|l|l|l|l|l|}
\hline Variables & $\begin{array}{l}\text { Pretreatment } \\
(\text { Mean } \pm \text { SD })\end{array}$ & $\begin{array}{l}\text { Post treatment } \\
(M e a n \pm S D)\end{array}$ & Z value & Df & p value\# \\
\hline Initiation & $8.95 \pm 1.96$ & $11.8 \pm 2.24$ & -3.985 & 19 & $0.001^{*}$ \\
\hline Negative assertion & $8.8 \pm 2.02$ & $10.25 \pm 1.92$ & -3.810 & 19 & $0.001^{*}$ \\
\hline Emotion support & $10.05 \pm 2.11$ & $11.05 \pm 2.01$ & -3.140 & 19 & $0.001^{*}$ \\
\hline Disclosure & $7.85 \pm 0.99$ & $9.7 \pm 1.45$ & -3.820 & 19 & $0.001^{*}$ \\
\hline $\begin{array}{l}\text { Conflict } \\
\text { management }\end{array}$ & $10.55 \pm 1.73$ & $11.65 \pm 1.66$ & -3.579 & 19 & $0.001^{*}$ \\
\hline
\end{tabular}

\# Wilcoxon Singed Rank Test, *Statistical Significant at 0.05

Significant increases in post test scores were observed for all the subscales: Initiation $(\mathrm{p}<.001)$, Negative Assertion ( $\mathrm{p}<.001)$, Emotional Support $(\mathrm{p}<.001)$, Disclosure $(\mathrm{p}<.001)$ and conflict Management $(\mathrm{p}<.001)$.

Within Group Analysis - Control Group

Table 7. Comparison of pre- and post-scores of Severity of Dependence for control group $(N=20)$.

\begin{tabular}{|l|l|l|l|l|l|}
\hline Variables & $\begin{array}{l}\text { Pretreatment } \\
\text { Mean } \pm \text { SD }\end{array}$ & $\begin{array}{l}\text { Post treatment } \\
\text { Mean } \pm \text { SD }\end{array}$ & Z value & Df & p value \# \\
\hline $\begin{array}{l}\text { Severity of } \\
\text { dependence }\end{array}$ & $11.80 \pm 1.40$ & $10.40 \pm 1.31$ & -4.064 & 19 & $0.001^{*}$ \\
\hline
\end{tabular}

\# Wilcoxon Singed Rank Test, *Statistical Significant at 0.05

Post test scores of Severity of Dependence $(\mathrm{p}<.001)$ were significantly lowered $(10.40 \pm 1.31)$ than the pretest scores $(11.80 \pm 1.40)$.

Table 8. Comparison of pre- and post-test scores of Brief Cope Questionnaire for control group $(N=20)$.

\begin{tabular}{|l|l|l|l|l|l|}
\hline Variables & $\begin{array}{l}\text { Pretreatment } \\
\text { Mean } \pm \text { SD }\end{array}$ & $\begin{array}{l}\text { Post treatment } \\
\text { Mean } \pm \text { SD }\end{array}$ & Z value & Df & p value\# \\
\hline Self-distraction & $4.00 \pm 1.41$ & $4.55 \pm 1.47$ & -3.051 & 19 & $0.001^{*}$ \\
\hline Active Coping & $4.9 \pm 1.17$ & $5.6 \pm 1.27$ & -2.594 & 19 & $0.001^{*}$ \\
\hline Denial & $4.25 \pm 1.80$ & $3.4 \pm 1.73$ & -3.494 & 19 & $0.001^{*}$ \\
\hline Substance use & $6.45 \pm 1.00$ & $2.7 \pm 0.47$ & -3.967 & 19 & $0.001^{*}$ \\
\hline
\end{tabular}




\begin{tabular}{|l|l|l|l|l|l|}
\hline Emotional support & $5.25 \pm 1.16$ & $5.85 \pm 1.27$ & -2.828 & 19 & $0.001^{*}$ \\
\hline $\begin{array}{l}\text { Instrumental } \\
\text { support }\end{array}$ & $6.75 \pm 1.74$ & $7.25 \pm 1.48$ & -2.500 & 19 & $0.01^{*}$ \\
\hline $\begin{array}{l}\text { Behavior } \\
\text { disengagement }\end{array}$ & $6.6 \pm 0.94$ & $5.6 \pm 0.60$ & -3.704 & 19 & $0.001^{*}$ \\
\hline Venting & $5.15 \pm 1.18$ & $5.95 \pm 0.94$ & -2.573 & 19 & $0.01^{*}$ \\
\hline Positive reframing & $3.25 \pm 0.97$ & $3.6 \pm 0.88$ & -1.941 & 19 & $0.05^{*}$ \\
\hline Planning & $5.75 \pm 1.33$ & $6.3 \pm 1.22$ & -3.051 & 19 & $0.001^{*}$ \\
\hline Humor & $3.75 \pm 1.29$ & $3.85 \pm 1.35$ & -.535 & 19 & 0.59 \\
\hline Acceptance & $6.00 \pm 1.03$ & $6.6 \pm 0.88$ & -3.207 & 19 & $0.001^{*}$ \\
\hline Religion & $5.9 \pm 1.48$ & $6.35 \pm 1.42$ & -2.183 & 19 & $0.03^{*}$ \\
\hline Self-blame & $6.4 \pm 1.10$ & $5.9 \pm 1.41$ & -2.673 & 19 & $0.001^{*}$ \\
\hline
\end{tabular}

\# Wilcoxon Singed Rank Test, *Statistical Significant at 0.05

Among all subscales, Self-distraction $(\mathrm{p}<.001)$, Active Coping $(\mathrm{p}<.001)$, Emotional Support $(\mathrm{p}<.001)$, Instrumental Support $(\mathrm{p}<.01)$, Venting $(\mathrm{p}<.01)$, Positive reframing $(\mathrm{p}<.05)$, Planning $(\mathrm{p}<.001)$, Acceptance $(\mathrm{p}<.001)$, Religion $(\mathrm{p}<.02)$ shown increase in post test scores. On the other hand, Denial $(\mathrm{p}<.001)$, Substance Use $(\mathrm{p}<.001)$, Behavior Disengagement $(\mathrm{p}<.001)$ and Self-blame $(\mathrm{p}<.001)$ shown mild decrease in post test scores. Only Humor subscale shown no significant changes in post test scores compared with pretest scores.

Table 9: Comparison of pre- and post-test scores of Emotion Regulation for control group ( $N=20)$.

\begin{tabular}{|l|l|l|l|l|l|}
\hline Variables & $\begin{array}{l}\text { Pre treatment } \\
\text { Mean } \pm \text { SD }\end{array}$ & $\begin{array}{l}\text { Post treatment } \\
\text { Mean } \pm \text { SD }\end{array}$ & Z value & Df & P value\# \\
\hline $\begin{array}{l}\text { Cognitive } \\
\text { reappraisal }\end{array}$ & $26.55 \pm 5.61$ & $28.55 \pm 5.49$ & -3.832 & 19 & $0.001^{*}$ \\
\hline $\begin{array}{l}\text { Expressive } \\
\text { suppression }\end{array}$ & $24.05 \pm 3.78$ & $23.6 \pm 4.20$ & -1.767 & 19 & 0.07 \\
\hline
\end{tabular}

\# Wilcoxon Singed Rank Test, *Statistical Significant at 0.05

Post test scores for Cognitive Reappraisal ( $\mathrm{p}<.001)$ shown significant increase. However, there is no significant change in post test scores of Expressive Suppression.

Table 10. Comparison of pre and post test scores of Interpersonal Competence Questionnaire for control group $(N=20)$.

\begin{tabular}{|l|l|l|l|l|l|}
\hline Variables & $\begin{array}{l}\text { Pretreatment } \\
\text { Mean } \pm \text { SD }\end{array}$ & $\begin{array}{l}\text { Post treatment } \\
\text { Mean } \pm \text { SD }\end{array}$ & Z value & Df & P value $^{\#}$ \\
\hline Initiation & $9.45 \pm 2.19$ & $9.80 \pm 2.17$ & -2.357 & 19 & .01 \\
\hline Negative assertion & $7.90 \pm 1.62$ & $8.30 \pm 1.22$ & -2.000 & 19 & $.04^{*}$ \\
\hline Emotion support & $9.90 \pm 1.68$ & $10.50 \pm 1.47$ & -3.014 & 19 & $.001^{*}$ \\
\hline Disclosure & $9.05 \pm 1.85$ & $9.55 \pm 2.04$ & -2.500 & 19 & $.01^{*}$ \\
\hline $\begin{array}{l}\text { Conflict } \\
\text { management }\end{array}$ & $8.30 \pm 1.72$ & $9.20 \pm 1.58$ & -4.025 & 19 & $.001^{*}$ \\
\hline
\end{tabular}

\# Wilcoxon Singed Rank Test, ${ }^{*}$ Statistical Significant at 0.05

All the 5 subscales of ICQ-15, Initiation ( $\mathrm{p}<.01)$, Negative Assertion ( $\mathrm{p}<.04)$, Emotional Support $(\mathrm{p}<.001)$,

Disclosure $(\mathrm{p}<.01)$ and Conflict Management $(\mathrm{p}<.001)$ shown increase in post test scores in control group patients. 


\section{Inter-Group Analysis for Experimental and Control Group}

Table 11. Comparison of post test scores of Severity of Dependence between experimental and control group $(N=40)$

\begin{tabular}{|l|l|l|l|l|l|}
\hline Variables & $\begin{array}{l}\text { Experimental } \\
\text { Mean } \pm \text { SD }\end{array}$ & $\begin{array}{l}\text { Control } \\
\text { Mean } \pm \text { SD }\end{array}$ & Z value & Df & P value $^{\#}$ \\
\hline $\begin{array}{l}\text { Severity of } \\
\text { dependence }\end{array}$ & $10.75 \pm 1.21$ & $10.50 \pm 1.27$ & -1.000 & 38 & .31 \\
\hline
\end{tabular}

\# Mann-Whitney U test, *Statistical Significant at 0.05

No significant differences during the treatment observed in Severity of Dependence between both the groups.

Table 12. Comparison of post test scores of cope brief questionnaire between experimental and control group $(N=40)$

\begin{tabular}{|l|l|l|l|l|l|}
\hline Variables & $\begin{array}{l}\text { Experimental } \\
\text { Mean } \pm \text { SD }\end{array}$ & $\begin{array}{l}\text { Control } \\
\text { Mean } \pm \text { SD }\end{array}$ & $\mathrm{Z}$ & $\mathrm{Df}$ & $\mathrm{P}_{\text {value }}$ \\
\hline Self-distraction & $4.70 \pm 1.22$ & $4.55 \pm 1.47$ & -2.715 & 38 & $.001^{*}$ \\
\hline Active Coping & $6.05 \pm 1.00$ & $6.45 \pm 1.32$ & -2.286 & 38 & $.02^{*}$ \\
\hline Denial & $2.80 \pm 1.11$ & $3.40 \pm 1.73$ & -.578 & 38 & .56 \\
\hline Substance use & $2.45 \pm .510$ & $2.70 \pm .470$ & -1.579 & 38 & .11 \\
\hline Emotional support & $6.55 \pm 1.05$ & $5.85 \pm 1.27$ & -1.988 & 38 & $.04^{*}$ \\
\hline $\begin{array}{l}\text { Instrumental } \\
\text { support }\end{array}$ & $6.70 \pm 1.17$ & $7.25 \pm 1.48$ & -1.205 & 38 & .22 \\
\hline $\begin{array}{l}\text { Behavior } \\
\text { disengagement }\end{array}$ & $5.75 \pm 1.02$ & $5.60 \pm .598$ & -.596 & 38 & .55 \\
\hline Venting & $5.80 \pm 1.36$ & $6.15 \pm .933$ & -2.718 & 38 & .001 \\
\hline Positive reframing & $3.80 \pm 1.11$ & $4.05 \pm .945$ & -2.426 & 38 & $.01^{*}$ \\
\hline Planning & $7.25 \pm .966$ & $6.30 \pm 1.21$ & -1.648 & 38 & .09 \\
\hline Humor & $3.45 \pm .60$ & $3.85 \pm 1.35$ & -1.012 & 38 & .31 \\
\hline Acceptance & $6.85 \pm 1.23$ & $6.60 \pm .883$ & -2.191 & 38 & $.02^{*}$ \\
\hline Religion & $4.55 \pm 1.54$ & $6.35 \pm 1.42$ & -3.459 & 38 & $.001^{*}$ \\
\hline Self-blame & $6.25 \pm 1.07$ & $5.90 \pm 1.41$ & -.196 & 38 & .84 \\
\hline
\end{tabular}

\# Mann-Whitney U test, *Statistical Significant at 0.05

Self-distraction $(\mathrm{p}<.001)$, Active Coping $(\mathrm{p}<.02)$, Emotional support $(\mathrm{p}<.04)$, Positive Reframing $(\mathrm{p}<.01)$ Acceptance (; $\mathrm{p}<.02)$ and Religion $(\mathrm{p}<.001)$ subscales have shown significant changes in post test scores between both the groups.

Table 13. Comparison of post test scores of Emotion Regulation between experimental and control group $(N=40)$

\begin{tabular}{|l|l|l|l|l|l|}
\hline Variables & $\begin{array}{l}\text { Pretreatment } \\
\text { Mean } \pm \text { SD }\end{array}$ & $\begin{array}{l}\text { Post treatment } \\
\text { Mean } \pm \text { SD }\end{array}$ & Z value & Df & p value $^{\#}$ \\
\hline $\begin{array}{l}\text { Cognitive } \\
\text { reappraisal }\end{array}$ & $27.30 \pm 4.08$ & $28.55 \pm 5.49$ & -.639 & 38 & .52 \\
\hline $\begin{array}{l}\text { Expressive } \\
\text { suppression }\end{array}$ & $23.20 \pm 5.83$ & $25.35 \pm 4.67$ & -1.428 & 38 & .15 \\
\hline
\end{tabular}

\# Mann-Whitney U test, *Statistical Significant at 0.05

No significant differences occurred in Emotional Regulation subscales between post test scores of Cognitive Reappraisals and Expressive Suppression. 
Table 14. Comparison of post test scores of Interpersonal Competence Questionnaire between experimental and control group $(N=40)$

\begin{tabular}{|l|l|l|l|l|l|}
\hline Variables & $\begin{array}{l}\text { Experimental } \\
\text { Mean } \pm \text { SD }\end{array}$ & $\begin{array}{l}\text { Control } \\
\text { Mean } \pm \text { SD }\end{array}$ & $\begin{array}{l}\text { z } \\
\text { value }\end{array}$ & Df & P value $^{\#}$ \\
\hline Initiation & $11.25 \pm 2.34$ & $9.80 \pm 2.17$ & -2.629 & 19 & $.001^{*}$ \\
\hline $\begin{array}{l}\text { Negative } \\
\text { assertion }\end{array}$ & $10.10 \pm 1.65$ & $8.30 \pm 1.22$ & -3.238 & 19 & $.001^{*}$ \\
\hline Emotion support & $11.05 \pm 2.01$ & $10.50 \pm 1.47$ & -1.514 & 19 & .13 \\
\hline Disclosure & $9.35 \pm 1.22$ & $9.55 \pm 2.04$ & -.618 & 19 & .54 \\
\hline $\begin{array}{l}\text { Conflict } \\
\text { management }\end{array}$ & $11.65 \pm 1.66$ & $9.20 \pm 1.58$ & -3.935 & 19 & $.001^{*}$ \\
\hline
\end{tabular}

\# Mann-Whitney U test, *Statistical Significant at 0.05

Out of 5 subscales of ICQ-15: Initiation $(\mathrm{p}<.001)$, Negative Assertion $(\mathrm{p}<.001)$ and Conflict Management $(p<.001)$ have shown significant changes. Emotional support and Disclosure scores showed no significant changes in post test scores.

\section{DISCUSSION}

Opioid dependence is a wide spread problem among people of all ages and socioeconomic groups. There are several social, environmental and lifestyle factors that contribute to dependency behavior. Chronic and excessive consumption of opioids as a coping mechanism is markedly toxic and increases the risk of physical and mental disorders ${ }^{[28]}$. The objectives of the study were to see the effect of DBT on severity of opioid dependence levels, distress tolerance, emotion regulation, and interpersonal effectiveness among patients with opioid dependence. The three variables included in the study are seen as having high correlation with controlling relapse and enhancing overall psychological well-being of the individual with opioid dependence[9]. The study will help in exploring the effectiveness of DBT skill training in patients with opioid dependence. In correspondence to the aim, pre and posttest control group design was best suited and opted. The sessions were meticulously planned prior to achieve the set goals with appropriate techniques.

The first objective was to find out the effect of DBT on severity of opioid dependence levels among the patients. No significant differences were observed between scores of both the groups. This suggest that both the groups appeared to reduce the level of severity for opioid dependence but the mean group difference for pre and post scores of experimental group is comparatively higher than that of control group. This supports us to reject null hypothesis. It has been postulated through several randomized clinical trials of DBT for substance abusers that there has been a decrease in substance abuse even in patients with borderline personality disorder ${ }^{[9]}$. It was suggested that this treatment may also be helpful for patients who have other severe disorders co- occurring with substance use disorders or who have not responded to other evidence based substance use therapies.

The second objective was to assess the effect of DBT on distress tolerance skills among patients with opioid dependence. DBT is based on assumption that people with variation of dysfunction in emotional regulation and under high stressful situations are often dealing with skill deficits and a significant lack of motivation, both of which contribute to the failure to utilize skillful coping skills in everyday life and continued substance abuse ${ }^{[29]}$. Distress tolerance skills help one to bear intense feelings without resorting to destructive or self-destructive strategies. The goal isn't necessarily to reduce the distress that one feels, but teach how to tolerate the pain and not do something that one would regret later, or which would make the situation even worse. Comparison of post treatment scores between both the groups based on The Brief cope questionnaire ${ }^{[21]}$ shows following six domains having higher score in experimental group as compared to control group after the intervention : Self-distraction, Active Coping, Emotional support, Acceptance, Positive

11 | KOMAL SANCHETI DR. NANDHA KUMARA PUJAM S.
Application of Dialectical Behavior Therapy in patients with opioid dependence - a pilot study 
Reframing and Religion. The results comprehend with another study where skills to improve distress tolerance (SIDI) appears to be brief and feasible intervention for use within inpatient substance use facilities and has a higher percentage of clinically significant improvement compared to patients in Supportive counseling and TAU ${ }^{[30]}$.Thus rejects the Null hypothesis. Conversely, post test score of Denial, Substance Use, Behavior Disengagement and Self-blame showed significant decrease which were considered as dysfunctional coping mechanisms. The decrease of dysfunctional coping strategies could be considered therapeutic mechanisms in addressing core clinical features of opioid use disorder. This finding is in line with both the DBT model ${ }^{[9,31]}$ and other third-wave cognitive treatments for SUDs (e.g., mindfulness-based relapse prevention, acceptance and commitment therapy) ${ }^{[32,34]}$. The within group comparison for control group also showed significant differences but the mean group difference for pre and post scores of experimental group is comparatively higher than that of control group. The subscales with dysfunctional coping mechanisms have shown no changes in post test scores. In current study intervention had significant impact on enhancing coping skills among these individuals thus, rejecting the null hypothesis. Distress tolerance skills help the client validate and strengthen healthy response, also to generalize the skills in everyday to do activities ${ }^{\text {[35] }}$

Often time's deregulated emotions will serve as a barrier to effective actions. Patients possess the ability to act effectively, but their emotions render them unable to do or say what they want. Accordingly, several empirical studies showed that negative mood and emotions are the most prominent factors determining craving and relapses ${ }^{[36,37]}$. Thus emotional regulation should be considered as a core dimension

involved in the treatment of SUDs ${ }^{[38,39]}$. Based on the scientific literature the third objective of the study was to see the effect of DBT in regulating emotions among the patients with opioid dependence, withholding null hypothesis. The between group comparison in current study showed no significant differences in post test scores of subscales: Cognitive Reappraisals and Expressive Suppression of Emotional regulation questionnaire ${ }^{[24]}$. However, when we compared the within group difference in experimental group there is a significant increase in post test scores of cognitive reappraisal subscale and significant decrease in scores of emotion suppression subscale. Whereas in control group there was only increase in post test scores of cognitive reappraisal subscale and no difference in post test scores of emotional suppression subscale. This indicated that DBT not only help the patients to reinterpret an emotion-eliciting situation in a way that alters its meaning and changes its emotional impact on them but also provide them with a safe environment where they no longer suppress/ restrict the outward expression of what they are feeling inside. Thus, there was a significant effect of DBT in regulating emotions among the patients with opioid dependence. Emotion regulation skills taught in DBT helps the patient to identify, regulate, and experience emotions without being overwhelmed and acting on impulse. These skills aim to reduce vulnerability and increase positive experiences. Emotion regulation skills teach clients to identify emotions elicited by the environment ${ }^{[40]}$.The result of current study is aligned with another study ${ }^{[41]}$ where in "emotion regulation training (DBT) proved more effective than cognitive therapy in increasing distress tolerance and emotional regulation enhancement"

Relationships can become strained under the weight of addiction. Families, relationships and work often suffer as person finds taking drugs as a priority above everything else. Interpersonal competence skills teach the recovering addict how to form meaningful, respectful relationships with new acquaintances as well as the people they may have harmed while under the influence. Dialectical behavior therapy uses Zen teachings to show the recovering addict how every decision they make, no matter how small, helps create their total self. The fourth objective of the study was to assess the effect of DBT on interpersonal competence skills among the patients with opioid dependence. The within group comparison for both experimental and control group have shown significant change in post test scores on all 5 domains of The Interpersonal Competence Questionnaire but the mean group difference for pre and post scores of experimental group is comparatively higher than that of control group. However, the between group comparison of post treatment scores have shown significant difference in 3 subscales: Initiation, Negative Assertion and Conflict Management than control group. Emotional support and Disclosure scores showed no significant changes in

12 |KOMAL SANCHETI DR. NANDHA KUMARA PUJAM S.
Application of Dialectical Behavior Therapy in patients with opioid dependence - a pilot study 
post test scores. Thus the finding of current study suggests that DBT was also helpful in improving interpersonal competence skills among the patients who've gone through it in comparison to those who were treated with only TAU. Hence, we reject our hypothesis partially. DBT is postulated to help clients interact with others in ways that allow them to improve relationships while simultaneously maintaining their own personal values, self-respect and wellbeing ${ }^{[35]}$. This skill training also helps the client regulate their emotions effectively leading to more interpersonal satisfaction ${ }^{[15]}$

Contemplating the above studies, which were collected after intensive search, it was found that impulsivity, poor coping and interpersonal skills are associated with substance abuse disorder and dependency in one or other ways. In the literature very few studies have been conducted to see effectiveness of DBT on patients with opioid dependence however DBT has proved effective in several other mental illnesses where substance dependence has been comorbid. The purpose of the skill training is to reduce the frequency, duration, and intensity of dysfunctional behaviors of clients and to provide a means to create meaningful and life worth living. On the basis of current study it can be said that DBT has been effective in reducing severity of opioid dependence, enhancing coping and interpersonal competence (in few domains) and better emotional regulation. The findings of this current study are more relevant in context of sample in present study. There is a need for further attempts to conduct large sample studies using both the genders and making assessment at different points of follow up to replicate and generalize the findings.

\section{CONCLUSION}

In the present study, there was a significant reduction in opioid dependence level, increasing distress tolerance, better emotional regulation and interpersonal competence with the help of DBT. Skills taught in DBT address to promote abstinence and to reduce the length and adverse impact of relapses relapse. Thus it can be concluded that DBT can be used effectively to treat individuals with substance dependence problems, both in conjunction with pharmacology and as a standalone. DBT skill training augments the effectiveness of pharmacotherapy and is more effective than TAU (medicine) or supportive counseling, working towards holistic wellbeing of the patient.

\section{REFRENCES}

1. Suh J, Ruffins S, Robins C, Albanese M, Khantzian E. Self-medication hypothesis: Connecting affective experience and drug choice. Psychoanalytic Psychology.2008; 25(3):518-532.

2. Merz F. United Nations Office on Drugs and Crime: World Drug Report 2017. 2017. SIRIUS - Zeitschrift für Strategische Analysen.2018; 2(1):85-86.

3. Degenhardt L, Whiteford H, Ferrari A, Baxter A, Charlson F, Hall W et al. Global burden of disease attributable to illicit drug use and dependence: findings from the Global Burden of Disease Study 2010. The Lancet.2013; 382(9904):1564-1574.

4. Ambekar A, Kumar R, Rao R, Agrawal A, Kumar M, Mishra AK. Punjab Opioid Dependence Survey. 2015. [Last cited on 2017 Jan 19]

5. Rao R. The journey of opioid substitution therapy in India: Achievements and challenges. Indian Journal of Psychiatry.2017; 59(1):39.

6. Smyth BP, Barry J, Keenan E, Ducray K. Lapse and relapse following inpatient treatment of opiate dependence. Ir Med J. 2010; 103:176-9.

7. Rao R. The journey of opioid substitution therapy in India: Achievements and challenges. Indian J Psychiatry. 2017; 59(1):39-45.

8. Linehan MM. A social-behavioral analysis of suicide and parasuicide: Implications for clinical assessment and treatment. In H. Glazer, \& J. F. Clarkin (Eds.). Depression, behavioral and directive intervention strategies. New York: Garland Press. 1981:229-294

9. Dimeff L, Linehan MM. Dialectical Behavior Therapy for Substance Abusers. Addiction Science \& Clinical Practice. 2008; 4(2):39-47.

13 |KOMAL SANCHETI

DR. NANDHA KUMARA PUJAM S.

Application of Dialectical Behavior Therapy in patients with opioid dependence - a pilot study 
10. Linehan MM. Cognitive-Behavioral treatment of borderline personality disorder. New York: Guilford.1993

11. Cristea IA, Gentili C, Cotet CD, Palomba D, Barbui C, Cuijpers P. Efficacy of psychotherapies for borderline personality disorder: A systematic review and meta-analysis. JAMA Psychiatry. 2017; 74(4), 319-328.

12. Dimeff L, Rizvi SL, Brown M, Linehan MM. Dialectical behavior therapyfor substance abuse: A pilot application to methamphetamine-dependent women with borderline personality disorder. Cognitive and Behavioral Practice.2000; 7(4), 457-468.

13. Valentine SE, Bankoff SM, Poulin RM, Reidler EB, Pantalone DW. The use of dialectical behavior therapy skills training as stand-alone treatment: systematic review of the treatment outcome literature. Journal of Clinical Psychology. 2015; 71(1):1-20.

14. Marco C, Mariagrazia M, Pietro R, Giulia V, Francesca P, Cesare M. Feasibility of dialectical behavior therapy skills training as an outpatient program in treating alcohol use disorder: The role of difficulties with emotion regulation and experiential avoidance Feasibility of dialectical behavior therapy skills training as an outpatient program in treating alcohol use disorder: The role of difficulties with emotion regulation and experiential avoidance. Addiction Research and Theory. 2019; 28.

15. Koerner K, Dimeff, LA. Overview of dialectical behavior therapy. In L. A. Dimeff \& K. Koerner (Eds.), Dialectical behavior therapy in clinical practice: Applications across Disorders and settings. New York: The Guilford Press.2017

16. Berking M, Margraf M, Ebert D, Wupperman P, Hofmann SG, Junghanns K. Deficits in emotion regulation skills predict alcohol use during and aftercognitive-behavioral therapy for alcohol dependence. Journal of consulting and Clinical Psychology.2011; 79(3), 307-318.

17. Kober H, Bolling D. Emotion regulation in substance use disorders. In J. J.Gross (Ed.). Handbook of emotion regulation(2 nd Ed.). New York (US): Guilford Press2014: 428-46

18. Tiffany ST, Friedman L, Greenfield SF, Hasin DS, Jackson R. Beyond drug use: A systematic consideration of other outcomes in evaluations of treatments for substance use disorders. Addiction.2012;107(4):709718.

19. ICD codes. 2013. ICD-10-CM Code F11.2 - Opioid Dependence. [online] Available at: $<$ https://icd.codes/icd10cm/F112> [Accessed 26 December 2020].

20. Lazarus RS, DeLongis A. Psychological stress and coping in aging. American Psychologist.1983; 38(3), 245254.

21. Carver CS. You want to measure coping but your protocol's too long: Consider the Brief COPE. International Journal of Behavioral Medicine.1997; 4: 92-100

22. Verdejo-García, A, Lawrence A, Clark L. Impulsivity as a vulnerability marker for substance-use disorders: Review of findings from high-risk research, problem gamblers and genetic association studies. Neuroscience \& Biobehavioral Reviews. 2008;32(4):777-810

23. Goldstein R, Volkow N. Drug Addiction and Its Underlying Neurobiological Basis: Neuroimaging Evidence for the Involvement of the Frontal Cortex. American Journal of Psychiatry. 2002; 159(10):1642-1652.

24. Gross JJ, John OP. Individual differences in two emotion regulation processes: Implications for affect, relationships, and well-being. Journal of Personality and Social Psychology.2003;85, 348-362.

25. Coroiu A, Meyer A, Gomez-Garibello CA, Brähler E, Hessel A, Körner A. Brief form of the Interpersonal Competence Questionnaire (ICQ-15): Development and preliminary validation with a German population sample. European Journal of Psychological Assessment.2015; 31(4):272-279.

26. Linehan MM. Diagnosis and treatment of mental disorders. Skills training manual for treating borderline personality disorder. Guilford Press.1993

27. Gossop M, Darke S, Griffiths P, Hando J, Powis B, Hall W, Strang J. The Severity of Dependence Scale (SDS): psychometric properties of the SDS in English and Australian samples of heroin, cocaine and amphetamine users. Addiction. 1995;90(5):607-14.

28. Minnerly C, Bressler S, Shokry I, Tao R. Estimating Mental Health Conditions of Patients with Opioid Use Disorder. Journal of Addiction. 2019;1-15.

14 | KOMAL SANCHETI

DR. NANDHA KUMARA PUJAM S.
Application of Dialectical Behavior Therapy in patients with opioid dependence - a pilot study 
29. Burmeister K, Höschel K, Barenbrügge J, Chrysanthou C, Rist F, Neacsiu A et al. Die Dialectical Behavior Therapy Ways of Coping Checklist (DBT-WCCL). Diagnostica. 2017.63(1), 29-41.

30. Bornovalova M, Gratz K, Daughters S, Hunt E, Lejuez C. Initial RCT of a distress tolerance treatment for individuals with substance use disorders. Drug and Alcohol Dependence.2012; 122(1-2):70-76.

31. Dimeff L, Sayrs J. Dialectical behavior therapy for substance-dependent individuals. In S. C. Hayes, \& M. E. Levin (Eds.). Mindfulness and acceptance for addictive behaviors. Applying contextual CBT to substance abuse \& behavioral addictions. Oakland: New Harbinger Publications.2012;69-101

32. Brewer J A, Bowen S, Smith JT, Marlatt GA, Potenza MN. Mindfulness-based treatments for co-occurring depression and substance use disorders: What can we learn from the brain? Addiction.2010; 105(10):1698-1706.

33. Witkiewitz K, Lustyk M K B, Bowen S. Retraining the addicted brain: A review of hypothesized neurobiological mechanisms of mindfulness-based relapse Prevention. Psychology of Addictive Behaviors.2013;27(2):351-365.

34. Hayes SC, Levin M. Mindfulness and acceptance for addictive behaviors: Applying Contextual CBT to Substance Abuse and Behavioral Addictions. New Harbinger Publications.2012

35. Choudhary S, Thapa K. Dialectical Behavior Therapy for Managing Interpersonal Relationships. Psychological Studies.2012;57(1), 46-54.

36. Gamble SA, Conner KR, Talbot NL, Yu Q Tu XM, Connors GJ. Effects of pretreatment and posttreatment depressive symptoms on alcohol consumption following treatment in project MATCH*. Journal of Studies on Alcohol and Drugs.2010;71(1):71-77.

37. Sinha, R.How does stress lead to risk of alcohol relapse? Alcohol Research: Current Reviews.2012; 34(4), 432-440

38. Berking M, Margraf M, Ebert D, Wupperman P, Hofmann SG, Junghanns K. Deficits in emotion regulation skills predict alcohol use during and aftercognitive-behavioral therapy for alcohol dependence. Journal of consulting and Clinical Psychology.2012;79(3):307-318.

39. Kober H, Bolling D. Emotion regulation in substance use disorders. In J. J.Gross (Ed.). Handbook of emotion regulation(2 nd Ed.). New York (US): Guilford Press.2014:428-46

40. Valentine SE, Bankoff SM, Poulin RM, Reidler EB, Pantalone DW. The use of Dialectical Behavior Therapy skills training as stand-alone treatment: A systematic review of the treatment outcome literature. Journal of Clinical Psychology.2015;71(1), 1-20.

41. Azizi A, Borjali A, Golzari M. The effectiveness of emotion regulation training and cognitive therapy on the emotional and addictional problems of substance abusers. Iran J Psychiatry. 2010;5(2):60-5. 